\title{
Contribution of Electronic Medical Record System to the Improvement of Safety and Quality in Clinical Practice as Perceived by Intensive Care Physicians
}

\author{
Haya Alkhatlan \\ Assistant Professor, Medical Records Department, College of Health Sciences, The Public Authority for Applied \\ Education and Training, Kuwait
}

\begin{abstract}
The Aim of this study was to examine the contribution of electronic medical record systems to the improvement of safety and quality in clinical practice as perceived by intensive care physicians. Subject: The researcher selected 120 physicians who completed and returned the questionnaires. Design: A quantitative survey research was employed. Tools: A task-oriented Questionnaire for Evaluating EMR Systems , Safety Attitudes Questionnaire( Short form) and Medical service quality( Short form) were used. Results: Findings indicated that electronic medical records achieve a better use, quality and satisfaction by intensive care physicians. There were significant correlations between electronic medical records systems, improved safety and improved quality. Conclusion and Recommendations: An electronic medical record system was found to be positively correlated with improved safety and improved quality. Improved safety was found to be positively correlated with improved quality. The findings have implications for using electronic medical record systems. Therefore, policy makers are invited to use electronic medical record systems. This they can be through training physicians and nurses about the use electronic medical record systems. The results of this study pointed to the importance of including the electronic medical record systems in medical programs.
\end{abstract}

Keywords: Clinical Practice, Electronic Medical Record Systems, Intensive Care Physicians, Quality \& Safety.

\section{Introduction}

Electronic Medical Records (EMRs),by definition, are computer- based medical information systems that are directed towards collecting, storing and displaying patient health information. With the help of EMRs intensive care physicians can take further step towards managing chronic disease, prevention, screening target patients, and hence improve patients' safety and quality in clinical practice (Manca, 2015).

Electronic Medical Records come to improve health care, facilitate transmission of patient data rapidly and accurately, make medical procedures standardized, help physicians make decision and allow for the prevention of medical errors in real time (Matthew, Rosa \& Rebekah, 2014).

Additionally , Electronic Medical Records give physicians the chance to screen and see a lot of patients through better access to comprehensive patient data which include clinical data. This in turn might prevent physicians from spending much time searching for patients' results and reports (Manca, 2015). They are efficient and cost-effective methods and tools which help improve the quality of services provided by healthcare professionals as well as the quality and accuracy of patient information (Khwima, Andrew \& Benjamin,2017).

Implementation of Electronic Medical Records help improve "the performance of health professionals, reduce operation/administrative costs and enhance patient safety. They also help improve healthcare quality by reducing medical errors " (Tom, Dean \& Tod, 2014).

Electronic Medical Records may be effectively used in health care industry ,hoping to help improving medical and healthcare procedures, common practice, regulations, public standards and protocols in order that they may produce patient outcomes and enhance patient safety (Ariffin, Ismail, Kadir, \& Kamal, 2018).

In Brazilian study about intensive care units, Junior, de Andrade \& de Carvalho (2018) found that the majority of 204 physicians who responded to the questionnaire used in this study $(84.6 \%)$ believed that the electronic system provided better quality than a paper system, and $76.7 \%$ believed that electronic systems provided greater safety than paper systems.

In A Kuwaiti study about primary health care, ALmutairi, Potts \& ALajmi (2018) reported that participants responded in a positive way, as $85 \%$ rated agreements on storage of radiographic images and records $(89 \%)$, sharing patient records with other dentists (96\%), and the potential for improving medical histories (98\%). Nevertheless, obstacles explained were software/hardware issues $(57 \%)$ and the need for technical training (55\%) and maintenance $(65 \%)$. 
Sharaf Eldin , Saad \& Samie (2013) concluded that the current status of electronic medical records adoption in Egypt had lag behind the international standards as just few hospital apply the system and many healthcare professionals were not aware of the system on one hand and its benefits on another.

\section{Aim of Study}

The purpose of this study was to examine the contribution of electronic medical record systems to the improvement of safety and quality in clinical practice as perceived by intensive care physicians.

\section{Problem Statement}

Though the importance of electronic recording systems in health care, their adoption and implementation in Egypt is often slow. The Egyptian government tried to adopt and implement electronic medical records in the few past years . Nevertheless, these trails were not completed. The first trial, which was an agreement had been done between Health Insurance Organization and the Data Management System Company, stopped in 2010, as was said for financial and political reasons (Elgaber, Abdel-Fattah \& Helal, 2017).

The second trial, which was an agreement between Health Insurance Organization and Siemens Company, stopped in 2010, as was said for financial reasons . The implementation had some administrative and technical barriers. In the third trial was a good point of start, however, the standard criteria were not discussed in details to ensure a complete implementation of medical record (Elgaber, Abdel-Fattah \& Helal, 2017).

At Assiut University Hospital had a trial to implement electronic recording systems in several hospitals and cancer institute in south Egypt and applied in nongovernment organization (57) and others.

The literature is limited concerning electronic recording systems and their impact on the quality and safety of healthcare, that is, there is a gap between the proposed and empirically evidenced benefits of electronic recording systems.

This study poses the following hypotheses

Hypothesis 1: Electronic medical records will be achieve a better use, quality and satisfaction by intensive care physicians.

Hypothesis 2:Electronic medical records will be improve patient safety.

Hypothesis 3: Electronic medical records will be improve quality of care .

Hypothesis 4: Electronic medical records will be mediate the link between improved safety and quality in clinical practice.

\section{Method \\ Design}

For the purpose of this study, quantitative survey research was employed. The independent variable is patient safety, quality of care is the dependent variable and electronic medical record is the moderating variable

Study setting:

Intensive care units in Heliopolis University Specialized (Obour) and Demerdash.

\section{Subjects}

For the purpose of this study, random sampling method was used to recruit the participants. The researcher selected 120 physicians who completed and returned the questionnaires. Physician candidates were selected from intensive care units in Heliopolis University Specialized (Obour) and Demerdash .The selection criterion was to be working in intensive care units. After obtaining the informed consent from the hospitals and physicians involved, a total of 120 $(62.5 \%$ males, and $37.5 \%$ females) physicians participated in this study. They ranged in age from 32 to 45 years $(M=39.88, S D=8.24)$. The researcher told those physicians that although he hoped that all physicians could continue with her till the end of this study, they were free to refuse or discontinue participation at any time. The researcher told those physicians that any information they would provide would be top secret and confidential . It would not be revealed to anyone.

\section{Instruments}

A task-oriented Questionnaire for Evaluating EMR Systems (Hallvard \& Arild, 2004). It is a24 items with a 5-point Likert scale from 1-5 (never, almost , slightly always, almost always, always). The reliability of the scale in terms of internal consistency was assessed by Cronbach's $\alpha$. The items demonstrated a satisfactory level of internal consistency reliability $(\alpha=0.74)$. For content validity, a panel of physicians informatics experts and the feedback from pilot tests provided evidence for the content validity of the questionnaire.

Safety Attitudes Questionnaire( Short form)( John et al., 2006) . It is a 24 items with a 5-point Likert scale from 1-5 ( 1 = disagree strongly, 2 = disagree slightly, $3=$ neutral, $4=$ agree slightly, $5=$ agree strongly).The SAQ has been adapted for use in intensive care units. The questionnaire takes approximately 10 to 15 minutes to complete. The reliability of the scale in terms of internal consistency was assessed by Cronbach's $\alpha$. The items demonstrated a satisfactory level of internal consistency reliability $(\alpha=0.89)$. For content validity, a panel of physicians informatics experts and 
the feedback from pilot tests provided evidence for the content validity of the questionnaire.

Medical service quality ( Short form) (Chang et al., 2017) It is a 22 items with a 5-point Likert scale from 1, indicating "very dissatisfied "to 5,"very satisfied". The questionnaire was originally based on Servqual. It was modified to concentrate on interpersonal relationship-based medical service valuation in the service encounter system. The instrument consists of four items covering facilities and environment, six items on service procedure, six items on physician performance, three items on administrative personnel and three items on treatment effectiveness. The questionnaire takes approximately 10 to 15 minutes to complete. The reliability of the scale in terms of internal consistency was assessed by Cronbach's $\alpha$. The items demonstrated a satisfactory level of internal consistency reliability $(\alpha=0.88)$.

\section{Pilot Study}

For face validity, a panel of physicians informatics experts and the feedback from pilot tests $(10 \%$ of subjects) provided evidence for the content validity of the questionnaire.

\section{Ethical considerations}

Physicians voluntarily participated in the study. They were free to discontinue responding to the questionnaires or in the study as a whole at any time. The researcher explained verbally about the study purposes privately before obtaining consent from each physician. Information collected in the study was kept strictly confidential, concealed, and it was used strictly for the purposes of this study. Sure ,there were neither known risks for participating in this study nor any incentives provided for participation.

\section{Procedures}

Physicians were visited in their place of work. Prior to administering the scales, they were notified and given the option of refusing to participate in the study. Physicians were informed about purpose of the study and voluntarily completed a consent form. To ensure that the physicians responded to the items honestly, they were told not to identify themselves in any way on the scale paper. They were also informed that their responses are for research purposes only and would be kept confidential. Each questionnaire took about 15-25 minutes to complete .Data were entered in Excel and SPSS files. 


\section{Results}

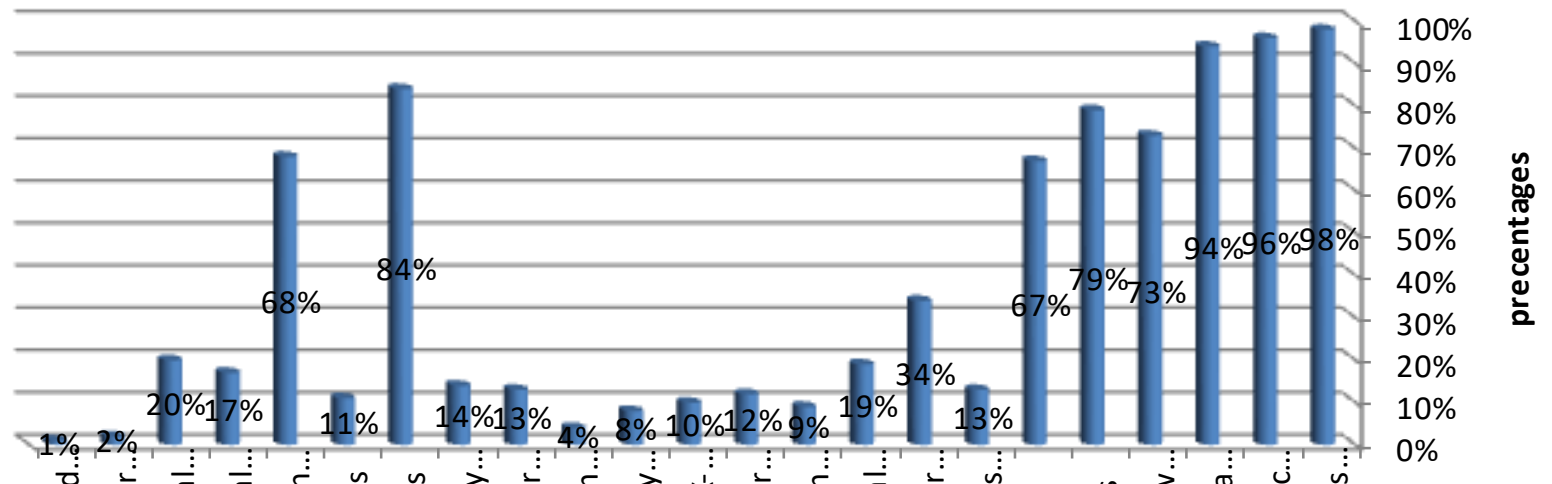

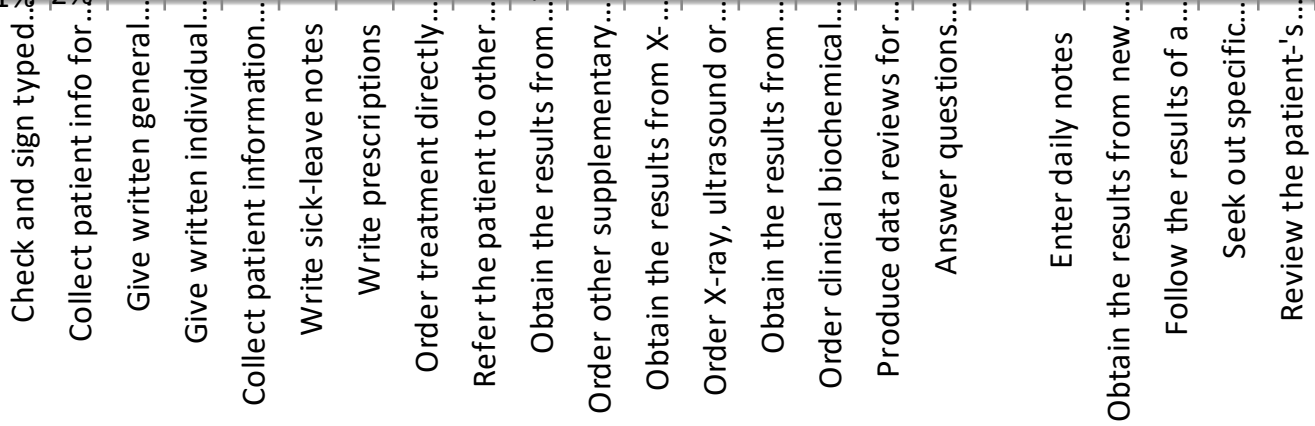

Figure(1): Percentages of use the personal computers for clinical tasks.

Table (1): Descriptive statistics and inter-correlations of electronic medical record systems, improved safety and improved quality.

\begin{tabular}{|l|c|c|c|}
\hline \multicolumn{1}{|c|}{ Variables } & $\mathbf{1}$ & $\mathbf{2}$ & $\mathbf{3}$ \\
\hline electronic medical record systems & 1.00 & & \\
\hline improved safety & $0.41^{* *}$ & 1.00 & 1.00 \\
\hline improved quality & $0.53^{* *}$ & $0.52^{* *}$ & 73.53 \\
\hline Mean & 76.80 & 81.79 & 5.21 \\
\hline Standard deviation & 5.92 & 6.15 & \\
\hline$* * \mathrm{P}<.01$ & \multicolumn{3}{|l}{} \\
\hline
\end{tabular}

Table (2): The regression results of the relationship between electronic medical record systems and improved safety. Model Summary b

\begin{tabular}{|c|c|c|c|c|c|c|c|c|c|}
\hline \multirow[b]{2}{*}{ Model } & \multirow[b]{2}{*}{$\mathbf{R}$} & \multirow{2}{*}{$\begin{array}{c}\mathbf{R} \\
\text { Square }\end{array}$} & \multirow{2}{*}{$\begin{array}{c}\text { Adjusted R } \\
\text { Square }\end{array}$} & \multirow{2}{*}{$\begin{array}{l}\text { Std. Error } \\
\text { of the } \\
\text { Estimate }\end{array}$} & \multicolumn{5}{|c|}{ Change statistics } \\
\hline & & & & & $\begin{array}{c}\text { R Square } \\
\text { change }\end{array}$ & F Change & Df1 & Df2 & $\begin{array}{c}\text { Sig. F } \\
\text { change }\end{array}$ \\
\hline 1 & 0.704 & 0.495 & 0.491 & 4.390 & 0.495 & 115.721 & 1 & 118 & 0.000 \\
\hline
\end{tabular}

a. Predictors: (Constant), EMRS

b. Dependent variable : Safety.

Table (3): The regression results of the relationship between electronic medical record systems and improved safety. a nova.

\begin{tabular}{|l|c|c|c|c|c|}
\hline \multicolumn{1}{|c|}{ Model } & Sum of Squares & df & Mean Square & F & Sig. \\
\hline $1 \quad$ Regression & 2231.025 & 1 & 2231.025 & \multirow{2}{*}{115.721} & \multirow{2}{*}{$0.000 \mathrm{a}$} \\
\hline Residual & 2274.067 & 118 & 19.279 & & \\
\hline Total & 4505.992 & 119 & & \\
\hline
\end{tabular}

a. Predictors: (Constant), EMRS

b. Dependent variable: Safety. 
Table (4): The regression results of the relationship between electronic medical record systems and improved safety. Coefficients a.

\begin{tabular}{|l|c|c|c|c|c|c|c|c|}
\hline \multirow{2}{*}{ Model } & \multicolumn{2}{|c|}{$\begin{array}{c}\text { Unstandarized } \\
\text { coefficients }\end{array}$} & $\begin{array}{c}\text { Standarized } \\
\text { coefficients }\end{array}$ & \multirow{2}{*}{$\mathbf{t}$} & \multirow{2}{*}{ Sig } & \multicolumn{3}{|c|}{ Correlations } \\
\cline { 2 - 3 } & $\mathbf{B}$ & Std error & Beta & & & Zero-order & Partial & part \\
\hline $1 \quad$ ( constant) & 31.833 & 5.778 & \multirow{2}{*}{0.704} & 5.509 & 0.000 & \multirow{2}{*}{0.704} & 0.704 & \multirow{2}{*}{0.704} \\
\hline EMRS & 0.684 & .064 & & 10.757 & 0.000 & & \\
\hline
\end{tabular}

b.Dependent variable : Safety.

Table (5): The regression results of the relationship between electronic medical record systems and improved quality . Model Summary b.

\begin{tabular}{|c|c|c|c|c|c|c|c|c|c|}
\hline \multirow[b]{2}{*}{ Model } & \multirow[b]{2}{*}{$\mathbf{R}$} & \multirow{2}{*}{$\begin{array}{c}\text { R } \\
\text { Square }\end{array}$} & \multirow{2}{*}{$\begin{array}{l}\text { Adjusted R } \\
\text { Square }\end{array}$} & \multirow{2}{*}{$\begin{array}{l}\text { Std. Error } \\
\text { of the } \\
\text { Estimate }\end{array}$} & \multicolumn{5}{|c|}{ Change statistics } \\
\hline & & & & & $\begin{array}{l}\text { R Square } \\
\text { change }\end{array}$ & F Change & Df1 & Df2 & $\begin{array}{c}\text { Sig. F } \\
\text { change }\end{array}$ \\
\hline 1 & $0.638 \mathrm{a}$ & 0.407 & 0.402 & 5.024 & 0.407 & 81.106 & 1 & 118 & .000 \\
\hline
\end{tabular}

a. Predictors: (Constant), EMRS

b. Dependent variable : Quality.

Table (6): The regression results of the relationship between electronic medical record systems and improved quality. Anova.

\begin{tabular}{|l|l|l|l|l|l|}
\hline \multicolumn{1}{|c|}{ Model } & \multicolumn{1}{c|}{ Sum of Squares } & \multicolumn{1}{c|}{ df } & \multicolumn{1}{c|}{ Mean Square } & \multicolumn{1}{c|}{ F } & \multicolumn{1}{c|}{ Sig. } \\
\hline $1 \quad$ Regression & 2047.500 & 1 & 2047.500 & 81.106 & $.000 \mathrm{a}$ \\
\cline { 1 - 4 } Residual & 2978.867 & 118 & 25.245 & & \\
\hline Total & 5026.367 & 119 & & & \\
\hline
\end{tabular}

a. Predictors: (Constant), EMRS

b. Dependent variable : Quality

Table (7): The regression results of the relationship between electronic medical record systems and improved quality. Coefficients a.

\begin{tabular}{|c|c|c|c|c|c|c|c|c|}
\hline \multirow[t]{2}{*}{ Model } & \multicolumn{2}{|c|}{$\begin{array}{c}\text { Unstandarized } \\
\text { coefficients }\end{array}$} & \multirow{2}{*}{$\begin{array}{c}\begin{array}{c}\text { Standarized } \\
\text { coefficients }\end{array} \\
\text { Beta }\end{array}$} & \multirow[t]{2}{*}{$\mathbf{t}$} & \multirow[t]{2}{*}{ sig } & \multicolumn{3}{|c|}{ Correlations } \\
\hline & B & Std error & & & & Zero-order & Partial & part \\
\hline 1 ( constant) & 34.713 & 6.612 & \multirow{2}{*}{638} & 5.250 & .000 & \multirow{2}{*}{638} & \multirow{2}{*}{638} & \multirow{2}{*}{638} \\
\hline EI & 0.655 & 0.073 & & 3.141 & .000 & & & \\
\hline
\end{tabular}

b. Dependent variable Qua

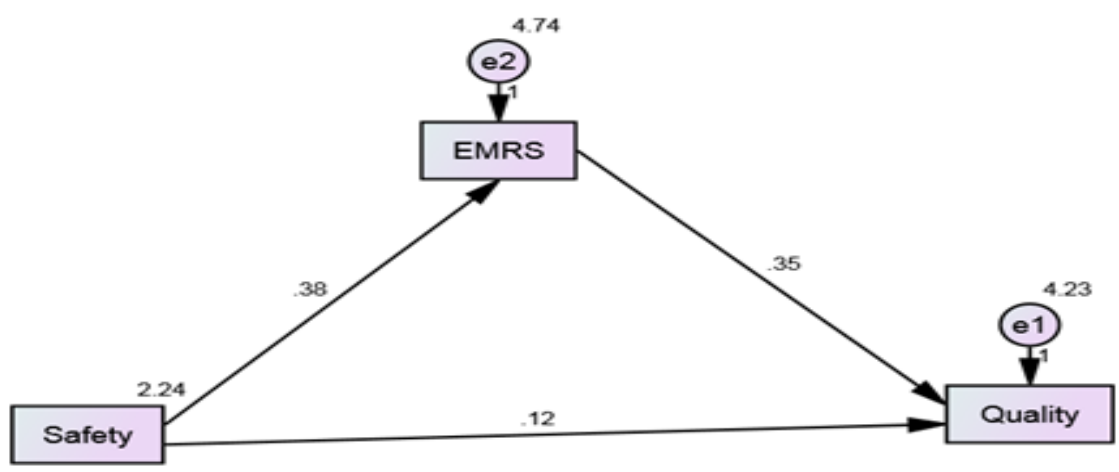

Figure (2): Regression Model of the Mediating Role of Electronic Medical Record Systems 
Table (8): Regression Weights: (Group number 1 - Default model)

\begin{tabular}{|l|l|l|r|r|r|r|c|}
\hline & & & \multicolumn{1}{c|}{ Estimate } & \multicolumn{1}{c|}{ S.E. } & \multicolumn{1}{c|}{ C.R. } & \multicolumn{1}{c|}{ P } & \multicolumn{1}{c|}{ Label } \\
\hline EMRS & $<---$ & Safety & .381 & .133 & 2.860 & .004 & \\
\hline Quality & $<---$ & EMRS & .354 & .087 & 4.082 & $* * *$ & \\
\hline Quality & $<---$ & Safety & .118 & .130 & .906 & .365 & \\
\hline
\end{tabular}

\section{Data analysis and Findings}

Pearson correlation and moderated hierarchical multiple regression analyses were conducted to test the hypotheses of the study. To verify hypothesis1" Electronic medical records achieve a better use, quality and satisfaction by intensive care physicians", tabular cum graphical form was used. As shown in Figure 1 Review the patient's problems came first with a percentage of $(98 \%)$, while Seek out specific information from patient records was ranked to be second with a percentage of $(96 \%)$. Follow the results of a particular test or investigation over time came third with a percentage of $(94 \%)$, while write prescriptions was ranked to be fourth with a percentage of $(84 \%)$. Enter daily notes came fifth with a percentage of $(79 \%)$, while obtain the results from new tests or investigations was ranked to be sixth with a percentage of $(73 \%)$.Collect patient information for various medical declarations was ranked to be seventh with a percentage of $(68 \%)$. Physicians ranked obtain information on investigation or treatment procedures to be eighth with a percentage of $(67 \%)$, while produce data reviews for specific patient groups, e.g. complication rate, diagnoses investigations was ranked to be ninth with a percentage of $(34 \%)$. Physicians ranked give written general medical information to patients to be tenth with a percentage of $(20 \%)$, while order clinical biochemical laboratory analyses was ranked to be eleventh with a percentage of (19\%). 17\% of the participants agreed to give written individual information to patients, e.g. about medications, disease status, while $14 \%, 13 \%, 12 \%$ and $11 \%$ agreed to order treatment directly (e.g. medicines, operations etc.), answer questions concerning general medical knowledge (e.g. concerning treatment, symptoms, complications etc.), order X-ray, ultrasound or CT investigations, and write sick-leave notes respectively. $10 \%, 9 \%, 8 \%, 4 \%, 2 \%$ and $1 \%$ agreed to obtain the results from X-ray, ultrasound or CT investigations, Obtain the results from clinical biochemical laboratory analyses, order other supplementary investigations, obtain the results from other supplementary investigations, collect patient information for discharge reports and check and sign typed dictations respectively.

\section{Descriptive data and inter-correlations}

Table (1): Shows the means, descriptive statistics and inter-correlations of electronic medical record systems, improved safety and improved quality. Table (1): Shows that there are significant correlations between of electronic medical record systems, improved safety and improved quality. Electronic medical record systems was found to be positively correlated with improved safety $(r=0.41)$, and improved quality $(\mathrm{r}=0.53)$. Improved safety was found to be positively correlated with improved quality $(r=0.52)$.

Testing the mediating role of electronic medical record systems in the relationship between improved safety and perceived improved quality. From Tables (2-4) it is clear that $\mathrm{R}^{2}=0.495$, Adjusted $\mathrm{R}^{2}=0.491$, which means that the independent variable, electronic medical record systems, explains $49.1 \%$ of the variability of the dependent variable, improved safety. The regression model is statistically significant, $\mathrm{F}=115.721, \mathrm{p}=$ 0.000. This indicates that, overall, the model applied can statistically significantly predict the dependent variable, improved safety.

From Tables (5-7): it is clear that $\mathrm{R}^{2}=0.407$, Adjusted $\mathrm{R}^{2}=0.402$, which means that the independent variable, electronic medical record systems, explains $40.2 \%$ of the variability of the dependent variable, improved quality. The regression model is statistically significant, $\mathrm{F}=81.106, \mathrm{p}=$ 0.000 . This indicates that, overall, the model applied can statistically significantly predict the dependent variable, improved quality.

According to Table (8): as for the effect of Safety on EMRS, the probability of getting a critical ratio as large as 2.860 in absolute value is 0.004 . In other words, the regression weight for Safety in the prediction of EMRS is significantly different from zero at the 0.05 level (two-tailed).As to the effect of EMRS on Quality, the probability of getting a critical ratio as large as 4.082 in absolute value is 0.001 . In other words, the regression weight for EMRS in the prediction of Quality is significantly different from zero at the 0.001 level (two-tailed). When the mediator (EMRS) mediates between Safety and Quality, the probability of getting a critical ratio as large as 0.906 in absolute value is 0.365 . In other 
words, the regression weight for Safety in the prediction of Quality is not significantly different from zero at the 0.05 level (two-tailed). This means that the relationship between independent variable(Safety) and dependent variable(Quality) became insignificant. This also means that EMRS is a mediator between Safety and Quality, and this mediation is complete one.

\section{Discussion}

The study examined the contribution of electronic medical record systems to the improvement of safety and quality in clinical practice as perceived by intensive care physicians. The findings of the present study confirmed that electronic medical record systems moderated the associations between patient safety and quality of care. In this regard, the findings extend our knowledge on the association between patient safety and quality of care by investigating the electronic medical record systems.

It can deducted that electronic medical record systems can be one of the effective mechanisms that healthcare organizations can use because they come to improve access to better information and integrates intelligent functions to safety and quality in clinical practice.

The findings of this study was in consistent with Manca, (2015) which indicated that electronic medical record systems were specifically found to be critical to quality improvement activities, as indicated by.

These findings are in the same line with Tom, et al., (2014) who explained that the benefits of an electronic health records were to add to healthcare efficiencies, large gains in quality and safety, and lower healthcare costs for consumers.

Moreover, Waithera, Muhia, Songole (2017), in their study, supported by the findings of this study, concluded that the electronic medical record systems have led to an increase in the productivity of healthcare delivery, better clinical decision making and better collaboration between healthcare providers. Furthermore, these systems help facilitate exchange of electronic information.

The findings of this study was in consistent with Waithera et al., (2017) which further indicated that there were increased patient participation and improved diagnostic and patient outcomes, as well as patient safety and quality of care. The most important factor was that most physicians believed the electronic medical record systems improved the quality of time with their patients and the quality of documentation in the records.

The findings of this study were consistent with those obtained by Tubaishat (2019) who found that electronic medical record systems directly or indirectly improved patient safety by minimizing medication errors, improving documentation of data, enhancing the completeness of data, and improving the sustainability of data.

The findings of this study revealed that electronic medical record systems help providing adequate access to enter data and retrieve patient's health information, and support, in a better way, for care decision making. This was in consistent with findings obtained by Tao \& Ping (2015) which indicated that they might improve feedback and communication among healthcare staff, facilitate compliance with medical procedure, and improve efficiency in information management and education.

Physicians perceive that the quality of the patient data is better when electronic medical record systems were easier to use and better aligned with their daily routine. This goes in the same line with findings by Mattijs, Hanneke \& Ferry (2017).

\section{Conclusion \& Recommendations}

In conclusion, the present study provided evidence that using electronic medical record systems improve patient safety. That will be through reducing medication errors, reducing adverse drug reactions and improving compliance to practice guidelines. We come to conclude that electronic medical record systems are important tools for improving healthcare quality and safety. Electronic medical record systems can be an important facilitating factor for patient safety and healthcare quality.

The findings have implications for using electronic medical record systems. Therefore, policy makers are invited to use electronic medical record systems. This they can be through training physicians and nurses about the use electronic medical record systems. The results of this study pointed to the importance of including the electronic medical record systems in medical programs.

It is recommended that policy makers take electronic medical record systems seriously and should be implemented in as more hospitals as possible.

\section{References}

1. ALmutairi B., Potts, H., \& ALajmi, N., (2018): Medical Dental Practitioners Assessments of Electronic Dental Record in Primary Health Care in Kuwait. Med. J. Cairo Univ., 86(3),1083-1091

2. Ariffin, N., bt N., Ismail, A., bt, Kadir, I., \& Kamal, J., (2018): Implementation of Electronic Medical Records in Developing Countries: Challenges \& Barriers. International 
Journal of Academic Research in Progressive Education and Development, 7(3), 187-199.

3. Chang Eun Kim, Joon-Shik Shin, Jinho Lee, Yoon Jae Lee, Me-riong Kim, Areum Choi, Ki Byung Park, Ho-Joo Lee \& In-Hyuk Ha (2017): Quality of medical service, patient satisfaction and loyalty with a focus on interpersonal-based medical service encounters and treatment effectiveness: across-sectional multicenter study of complementary and alternative medicine(CAM) hospitals. BMC Complementary and Alternative Medicine, $17: 174$

4. Elgaber, S., Abdel-Fattah, M., \& Helal, S., (2017): A Roadmap to Implement EHR Nationwide in Egypt. Communications on Applied Electronics (CAE), 7(6), 18-28.

5. Hallvard L., \& Arild F., (2004): Task-oriented evaluation of electronic medical records systems: development and validation of a questionnaire for physicians. BMC Medical Informatics and Decision Making, 4:1

6. John B., Sexto, Robert L., Helmreich, Torsten B Neilands, Kathy Rowan, Keryn Vella, James Boyden, Peter R., Roberts \& Eric J., Thomas (2006): The Safety Attitudes Questionnaire: psychometric properties, benchmarking data, and emerging research. BMC Health Services Research, 6:44

7. Junior, J., de Andrade, A., \& de Carvalho, W., (2018): Evaluation of the use of electronic medical record systems in Brazilian intensive care units. Rev Bras Ter Intensiva., 30(3):338346

8. Khwima E., Andrew K., \& Benjamin K., (2017): Factors affecting the utilisation of electronic medical records system in Malawian central hospitals. Malawi Med J. ,29(3): 247253.

9. Manca, P., (2015): Do electronic medical records improve quality of care? Yes . Canadian Family Physician,61(10): 846-847.

10. Matthew C., Rosa R.,. \& Rebekah L., (2014): Perceptions of Electronic Health Record Implementation: A Statewide Survey of Physicians in Rhode Island. The American Journal of Medicine 127(10),DOI: 10.1016/j.amjmed.2014.06.011.

11. Mattijs, S., Hanneke, W., \& Ferry, K., (2017: Use of electronic medical records and quality of patient data: different reaction patterns of doctors and nurses to the hospital organization. Medical Informatics and Decision Making ,17:17 DOI 10.1186/s12911-017-0412
12. Otieno, O., Toyama, H., Asonuma, M., Kanai-Pak, M., \& Naitoh, K., (2007): Nurses' views on the use, quality and user satisfaction with electronic medical records: Questionnaire development. J. Adv. Nurs. 60(2):209-219

13. Sharaf Eldin, A., Saad, D., \& Samie, G., (2013): Evaluation of Electronic Health Records Adoption in Egypt. International Journal of Engineering Research and Applications(IJERA), 3(1),1131-1134

14. Tao Jiang \& Ping Y., (2014): The Impact of Electronic Health Records on Client Safety in Aged Care Homes. Nursing Informatics , K. Saranto et al. (Eds.) doi:10.3233/978-1-61499415-2-116

15. Tom, S., Dean, F., \& Tod, G., (2014): Electronic Health Records (EHR). American Journal of Health Sciences, 3(3), 201-210.

16. Tubaishat, I., (2019): The effect of electronic health records on patient safety: A qualitative exploratory study. Inform Health Soc Care. ,44(1):79-91

17. Waithera L., Muhia J., Songole R., (2017): Impact of Electronic Medical Records on Healthcare Delivery in Kisii Teaching and ReferralHospital. Med Clin Rev. 3 (4) 21. 